\title{
Patterns of genetic variation and life history traits of Zeuxapta seriolae infesting Seriola lalandi across the coastal and oceanic areas in the southeastern Pacific Ocean: potential implications for aquaculture
}

\author{
Fabiola A Sepúlveda ${ }^{1 *}$ and M Teresa González ${ }^{2}$
}

\begin{abstract}
Background: The monogenean, Zeuxapta seriolae, is a host-specific parasite that has an extensive geographical distribution on its host, Seriola lalandi, and is considered highly pathogenic in farmed fish. In recent years, developing cultures of S. Ialandi in different coastal localities in Southeastern Pacific Ocean (SEP) have been affected by moderate and heavy infections of this parasite, attributed to contagion from wild to farmed fish. Here, we evaluated the pattern of genetic variations and biological traits of $Z$. seriolae in a spatial and temporal scale across its geographical distribution in SEP to determine its genetic status and biological traits, which could affect its transmission dynamics from wild to farmed fish.

Methods: Wild fish and their parasites were sampled from fisheries in the northern Chilean coast (NCC: $24^{\circ} \mathrm{S}-30^{\circ} \mathrm{S}$ ) and Eastern islands (JFA: ca 33 ${ }^{\circ}$; $80^{\circ} \mathrm{W}$ ) between 2012 and 2014. Fragments of 816 bp of the cytochrome $c$ oxidase subunit I (COI) gene was sequenced for 112 individuals from NCC and 63 from JFA and compared using AMOVA. Prevalence and intensity of $Z$. seriolae were calculated for each area. The parasite body size, fecundity and size at sexual maturity were estimated for 177 parasites from NCC and 128 from JFA, and significant differences were evaluated using GLM.

Results: Geographical genetic structuring was detected for Z. seriolae across SEP, with a population in NCC and the other in JFA, both with the same high haplotype diversity. Neutrality tests and mismatch analyses indicated that both Z. seriolae populations are stable. Parasite biological traits such as fecundity, body size, and size at sexual maturity, and population parameters varied significantly between geographical areas.

Conclusion: Two genetic groups of Z. seriolae were detected in wild fish across SEP. Because of the seasonal migration of wild host and temporal contact with farming, quantifying the genetic diversity and level of gene flow or isolation between parasite populations is useful for fish health management in farming. The smallest size of sexual maturity in parasites from NCC is predictive of shorter life cycles, and their high genetic diversity suggests high evolutionary potential and high transmission of this parasite to farmed hosts.
\end{abstract}

Keywords: Biological traits, COI, Fish, Genetic diversity, Monogenea, Genetic structure

\footnotetext{
* Correspondence: fabiolasepu@gmail.com

'Programa Ciencias Aplicadas, mención Sistemas Marinos Costeros, Universidad de Antofagasta, P.O. Box 170, Antofagasta 1240000, Chile Full list of author information is available at the end of the article
} 


\section{Background}

Patterns of genetic diversity or variations among parasite populations can provide clues to the population life histories and degree of evolutionary isolation, which may have important applications in aquaculture and epidemiology $[1,2]$. Therefore, the population genetic structure of a parasite, which is associated with the amount of genetic exchange between subpopulations, allows for understanding the parasite's dispersal capabilities and identifying a source of infection on a spatial scale, which contributes to the control of diseases [2]. The extent of geographic variations in gene frequency in most species is the result of the geographic distance between subpopulations and is associated with variations in the oceanographical conditions [3-5]. Further, balances among mutation, genetic drift, selection and genetic flow can produce either local genetic differentiation or genetic homogeneity [6]. Of these aspects, gene flow, which includes all mechanisms that result in the movement of genes from one population to another, determines the extent to which each local population of a species is an independent evolutionary unit [7, 8]. For parasites, genetic flow among populations also depends on the intrinsic host-parasite relationship $[9,10]$. Therefore, high or low genetic flow in parasite populations has important implications for evolutionary processes, such as host-race formation, adaptation to host defenses, and the evolution of drug resistance [11]. Moreover, it has been hypothesized that a pathogen population with high evolutionary potential, which is the potential to generate new variations in traits that determine host-parasite interactions and the evolution of disease dynamics [12], is associated with high mutation rates, high potential for gene flow and a large population effective size $\left(\mathrm{N}_{\mathrm{e}}\right)$, each of which allows for the increase of genetic diversity and presents a higher risk of breaking down resistance genes [13].

The genetic structure of parasite populations is associated with host specificity, host mobility and environmental conditions [9]. The dispersal ability of parasites with low host specificity and in the absence of physical barriers greatly facilitates extensive gene exchange among different subpopulations $[12,14,15]$. Alternatively, host specific parasites are more likely to experience frequent local extinction and re-colonization events, particularly in small and fragmented wild host populations. These population processes may promote the loss of genetic diversity within a parasite population and generate genetic differences among populations through genetic drift [12]. Additionally, the potential spatial distribution of a parasite not only depends on the dispersal stages of parasites (the free living stages, e.g., eggs, oncomiracidium larvae, and nauplius larvae) but is also closely coupled with host mobility (sedentary or highly mobile), thereby facilitating the homogenization of a parasite population and allowing for the potential evolution and spread of drug resistance in parasites [16], as demonstrated for terrestrial nematodes [11] and marine hosts [17], freshwater trematodes [16] and marine monogeneans [15].

In marine systems, oceanographic conditions and the distance between populations can determine the geographic genetic patterns in parasites $[18,19]$ and, similarly, differences in parasite biological traits. Environmental parameters, such as temperature and salinity in different latitudes, may affect the egg production rate, egg-hatching time and development to sexual maturity in marine ectoparasites because these occur more quickly at warmer temperatures and can trigger different infection dynamics [20-22].

Population genetic studies provide insight into parasite evolutionary histories and aid in the identification of the causal factors contributing to disease dynamics and distribution [12]. The monogenean, Zeuxapta seriolae, is reported in Seriola lalandi from Australia, New Zealand, Japan and California and in S. dumerili from the Mediterranean Sea [23-26]. The genus Zeuxapta is specific to the genus Seriola, and Z. seriolae, and shows a particularly wide geographic distribution in both farmed and wild fish. Additionally, Z. seriolae is considered highly pathogenic in farmed fish because at high intensities, it can kill its host by causing anaemia [25, 27-30].

The yellowtail kingfish $S$. lalandi is a pelagic fish and is highly migratory and widely distributed in temperate and subtropical waters of the world. In the SEP, S. lalandi present a permanent population in an archipelago approximately $700 \mathrm{~km}$ from continental Chile $\left(80^{\circ} \mathrm{W}\right)$, where it is captured year-round. On the northern continental Chilean coast (NCC: $20^{\circ} \mathrm{S}$ to $30^{\circ} \mathrm{S}$ ), this species arrives annually in the summer, most likely to feed, as occurs in the southwest Atlantic Ocean [31]. No spawning and nursery areas are known in SEP. In recent years, cultures of $S$. lalandi have been initiated at different localities in the NCC, where farmed fish are affected by moderate and heavy infection levels of this parasite, which has been attributed to contagion from wild to farmed fish.

Because Z. seriolae is a host specific parasite that has an extensive geographic distribution (cosmopolitan) and affects the aquaculture of S. lalandi worldwide it is important to know its evolutionary potential, which can be useful for understanding the dynamic of the disease. Here, we evaluated the patterns of genetic variation of this monogenean on spatial and temporal scales using mitochondrial DNA markers. Additionally, we estimated several life history traits, such as fecundity and size at sexual maturity, beside population parameters of infection across the geographic distribution in the SEP. Taking into account that the host population migrates in the summer to the coast in the SEP (extending the 
fishery from $20{ }^{\circ} \mathrm{S}$ to $30{ }^{\circ} \mathrm{S}$ ) but the host migratory route, fish origin and the effect of physical barriers on the dispersal of parasite population are not known, we can expect that parasite populations correspond to a single panmictic population. Alternatively, if physical barriers or host segregation affect the genetic flow of parasites, we can expect genetic structure of $Z$. seriolae across the SEP.

\section{Methods}

\section{Sampling areas and collection of parasites}

Parasites were collected off 393 wild S. lalandi fish captured by commercial fishers from two geographical areas (coastal and oceanic) across the SEP. Fish from the oceanic area (JFA: $33^{\circ} \mathrm{S}, 80^{\circ} \mathrm{W}$ ) were collected between April and August of 2013-2014. Fish from the coastal area were collected from different sites during summer (January and April) between 2012 and 2014 because fishing of S. lalandi extends from $20^{\circ} \mathrm{S}$ to $30^{\circ} \mathrm{S}$ varying the fish landing sites between years. The sampled sites/ year in the NCC were: Antofagasta/2013, 2014 (AF: $\left.24{ }^{\circ} \mathrm{S}, 70^{\circ} \mathrm{W}\right)$, Chañaral $/ 2012\left(\mathrm{CH}: 26^{\circ} \mathrm{S}, 70^{\circ} \mathrm{W}\right)$ and Coquimbo/2014 (CQ: $\left.30^{\circ} \mathrm{S}, 71^{\circ} \mathrm{W}\right)$ (Fig. 1).

For molecular analyses, only one parasite per fish was used in 123 fish to prevent the sampling of inbred offspring [14]. Two parasites per fish were collected from 23 fish to increase the number of parasites by locality and year. In only two cases, three parasites from one fish were used to prior check that they were not clones. Specimens of monogenean $Z$. seriolae were removed from the gills of fish, counted and identified using a stereomicroscope, and each parasite was placed individually into

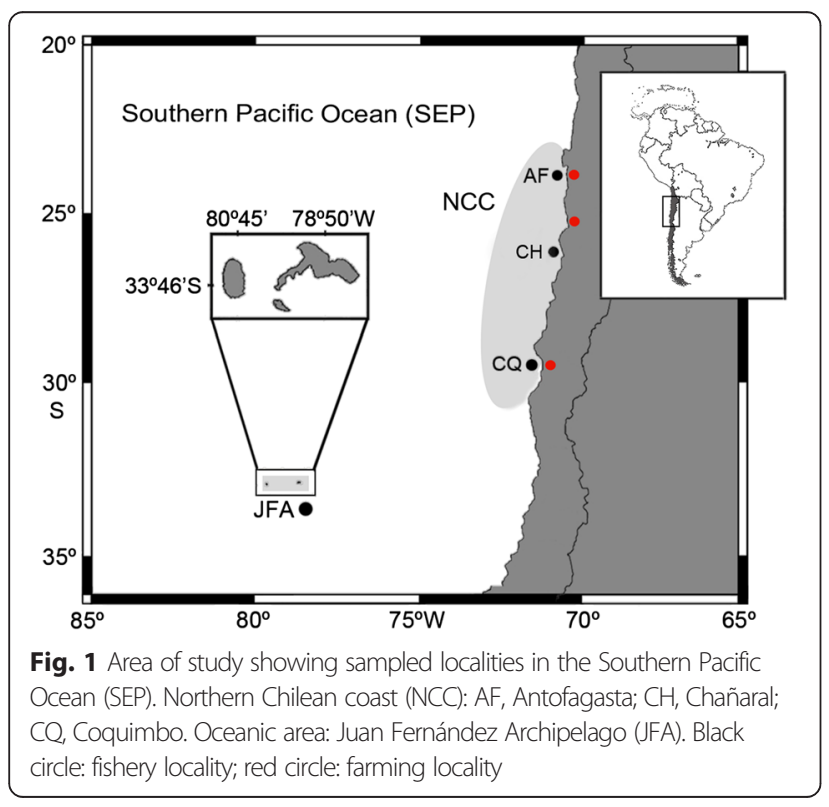

a $1.5 \mathrm{ml}$ Eppendorf tube with absolute ethanol for DNA extraction.

\section{DNA extraction, amplification and sequencing}

DNA was extracted using the QIAamp Tissue kit (Qiagen, Germany) according to the manufacturer's instructions. The DNA was then eluted into $50 \mu \mathrm{l}$ of nuclease free water. Mitochondrial gene cytochrome $c$ oxidase 1 (COI) was amplified using forward primer JB3 (5'TTTTTTGGGCATCCTGAGGTTTAT-3') and reverse primer COX1 (5'AATCATGATGCAAAAGGTA-3') as described by Leung et al. [32]. Each PCR reaction had a final volume of $35 \mu \mathrm{l}$ including: 5 units of $\mathrm{GoTaq}^{\circ} \mathrm{DNA}$ polymerase (Promega), $7 \mu \mathrm{l} 5 \mathrm{X}$ PCR buffer, $5.6 \mu \mathrm{l}$ $\mathrm{MgCl} 2(25 \mathrm{mM}), 2.1 \mu \mathrm{l} \mathrm{BSA}(10 \mathrm{mg} / \mathrm{ml}), 0.7 \mu \mathrm{l}$ of deoxynucleotide triphosphate (dNTP) $(10 \mathrm{mM}), 10 \mathrm{pM}$ of each primer and $5 \mu \mathrm{l}$ template DNA. The thermocycling programme included: an initial denaturation step at $95^{\circ} \mathrm{C}$ for $2 \mathrm{~min}$ followed by 40 cycles of amplification at $95^{\circ} \mathrm{C}$ for $30 \mathrm{~s}, 48^{\circ} \mathrm{C}$ for $40 \mathrm{~s}$ and $72{ }^{\circ} \mathrm{C}$ for $1 \mathrm{~min}$, with a final extension step at $72{ }^{\circ} \mathrm{C}$ for $10 \mathrm{~min}$. PCR products were purified using E.Z.N.A ${ }^{\bullet}$ Cycle-Pure PCR Purification Kit (Omega Bio-Tek, Inc., Atlanta, Georgia, USA), and both DNA strands were directly sequenced (Macrogen, Seoul, Korea; http://www.macrogen.com).

\section{Data analyses}

Sequences were edited using ProSeq v 2.9 beta [33] and aligned using Clustal 2 software package [34].

\section{Genetic diversity and population structure}

Molecular diversity was estimated through the following indices: number of haplotypes $(\mathrm{H})$, number of polymorphic sites $(\mathrm{S})$, haplotype diversity $(\mathrm{H} d$ : a measure of the frequencies and numbers of haplotypes among individuals [35]), nucleotide diversity ( $\pi$ : average weighted sequence divergence between haplotypes [35]) and mean number of pairwise differences $(k)$ that were computed using Dnasp 5.0 [36] and Arlequin v3.1 [37]. Genetic distance within locations and between localities was estimated using Mega 6.0 [38]. Mann Whitney U test were used to evaluate differences in genetic diversity of $Z$. seriolae between geographical areas.

Genetic population structures were examined through AMOVA to determine the amount of genetic variability using F-statistics in three temporally subdivided hierarchical levels: the proportion of variations among years $\left(\mathrm{F}_{\mathrm{ct}}\right)$, among populations within years $\left(\mathrm{F}_{\mathrm{sc}}\right)$ and within populations $\left(\mathrm{F}_{\mathrm{st}}\right)$. The significance of the covariance component associated with different possible levels of genetic structure was permuted 10,000 times. Pairwise genetic differentiation between populations was estimated using the fixation index $F_{\text {st }}$ and statistical significance was 
tested with 10,000 permutations. Both analyses were performed in Arlequin v3.1.

\section{Demographic analysis}

Episodes of population growth or decline show characteristic signatures in the distribution of nucleotides between pairs of individuals that in $Z$. seriolae were evaluated with mismatch distribution analysis in each locality and year and for total samples, with analysis performed using Dnasp 5.0. Unimodal distribution and multimodal distributions were thereby distinguished for historic expansion and population equilibrium, respectively [39].

In addition, two neutrality tests were performed in Arlequin v3.1 software: Tajima's D [40] and Fu F statistics [41]. Both neutrality tests provide predictions about evolution under mutation-drift equilibrium in the absence of systematic effects such as selection or demographic effects. Thus, significant deviations from neutrality can be a consequence of selection, population expansions, bottlenecks or demographic fluctuations [42].

Finally, a haplotype network was constructed using HaploViewer (http://www.cibiv.at/ greg/haploviewer, Center for Integrative Bioinformatics Vienna) previous construction of a neighbour-joining tree (TN93 + G model) in Mega v6. All sequences were deposited in GenBank under accession number: KP119183-KP119357.

\section{Population parameters, fecundity and body size}

Prevalence and intensity of $Z$. seriolae were calculated according to Bush et al. [43] for years, sites and geographical areas. The median intensity was used as descriptor of central tendency because data do not show normal distribution [44]. Three hundred and five $Z$. seriolae specimens were randomly selected to estimate parasite body length and fecundity by year, site and geographical area. Each parasite was individually examined in a slide with a drop of water and cover slip. Measurements were carried out using Micrometrics 5.0 software (New York Microscope Company, Inc.), which was connected to an Olympus camera. The total length (in millimeters) included the opisthaptor length.

Parasite fecundity was measured as number of eggs per parasite. For this, the parasite uterus was dissected and an entire chain of eggs was removed and counted using a manual counter. To evaluate differences in fecundity, only those parasites whose uteri contained over 50 eggs were considered to exclude those parasites just starting their egg production.

The size at first sexual maturity (= first size egg production) was measured as the parasite length when $50 \%$ of the population of $Z$. seriolae contained at least one egg within the uterus [45] for each fishing area. For this estimation, all examined parasites (with and without eggs $)$ were used $\left(\mathrm{n}_{\mathrm{NCC}}=590 ; \mathrm{n}_{\mathrm{JFA}}=158\right)$. The parasite length was categorized in $\mathrm{mm}$ ( $1 \mathrm{~mm}$ to $25 \mathrm{~mm}$ ).

$2 \times 2$ contingency tables with Yates correction were used to evaluate prevalence between geographical areas and temporal variations for sites AF (coastal) and JF (oceanic). Mann Whitney $U$ tests were used to evaluate differences in intensity of $Z$. seriolae between geographical areas and to compare the parasite total length between the NCC and JFA samples. The Spearman correlation was used to evaluate the association between parasite body length and number of eggs [44]. Generalized linear models were used to evaluate differences in intensity of infection and parasite fecundity between geographical areas. Fish size was used as co-variable for intensity, and total parasite length was used as co-variable for fecundity. For both models, we used the poisson distribution for response variable and the log as the function link [46]. All analyses were performed using Statistica 7.0 software (Statsoft Inc., Tulsa, Oklahoma).

\section{Results}

\section{Genetic diversity and population structure}

A 816 bp segment of the COI gene was obtained from $175 \mathrm{Z}$. seriolae individuals sampled from the two geographical areas: 112 sequences from the NCC and 63 sequences from the JFA (Table 1). Sequence variability between NCC and JFA was $0.5-0.9 \%$, while intralocality variability was $0.4-0.8 \%$.

A total of 48 polymorphic sites led to the definition of 61 haplotypes (Table 1), 27 of which were unique to the JFA (44.3\%), whereas another 10 haplotypes (H1, H2, H3, H4, H5, H6, H8, H9, H19, H36) were shared among the different areas (NCC and JFA, 16.4\%), and 24 haplotypes were unique to the NCC (39.3\%). Among the shared haplotypes, $\mathrm{H} 1$ and $\mathrm{H} 5$ were the most frequent haplotypes, with $90 \%$ of $\mathrm{H} 1$ predominant in the NCC and $58 \%$ of $\mathrm{H} 5$ predominant in the JFA (Fig. 2).

Genetic diversity indices of $Z$. seriolae within and between geographic areas are summarized in Table 1. Total haplotype diversity considering the entire region of study was $0.91 \pm 0.01$, and nucleotide diversity was $0.007 \pm 0.0001$. The haplotype diversity did not differ between geographical areas $(\mathrm{U}=37.5 ; p=0.42)$, but nucleotide diversity was significantly lower in JFA $(U=9$; $p=0.002$; Table 1).

Hierarchical AMOVA analysis revealed significant genetic differentiation at the spatial scale $\left(\mathrm{F}_{\mathrm{st}}=0.1286\right.$, $\left.\mathrm{p}<0.05 ; \mathrm{F}_{\mathrm{sc}}=0.1354, \mathrm{p}<0.05\right)$. Eighty-seven percent of the variance was explained by variability within populations and $13 \%$ of the remaining genetic variation was attributed to variability among populations within years (Table 2). Parasites from JFA were significantly different 
Table 1 Genetic diversity and neutrality test for Zeuxapta seriolae by sampling localities and years

\begin{tabular}{llllllllll}
\hline Area & Site-year & $\mathrm{N}$ & $\mathrm{H}$ & $\mathrm{S}$ & $\mathrm{Hd}$ & $\pi$ & $K$ & Tajima's $D$ & Fu's $\mathrm{F}_{\mathrm{S}}$ \\
\hline NCC & CH-2012 & 14 & 6 & 12 & $0.79 \pm 0.09$ & $0.004 \pm 0.0014$ & 3.28 & -0.51 & 0.34 \\
& AF-2013 & 41 & 13 & 21 & $0.85 \pm 0.04$ & $0.006 \pm 0.0006$ & 5.26 & 0.24 & -0.41 \\
& AF-2014 & 26 & 15 & 24 & $0.89 \pm 0.05$ & $0.007 \pm 0.0006$ & 5.96 & -0.19 & -3.25 \\
& CQ-2014 & 31 & 17 & 25 & $0.91 \pm 0.04$ & $0.007 \pm 0.0004$ & 6.14 & -0.06 & -3.84 \\
& TOTAL NCC & 112 & 34 & 40 & $0.88 \pm 0.02$ & $0.007 \pm 0.0003$ & 5.59 & -0.80 & $-11.51^{*}$ \\
JFA & JF-2013 & 36 & 20 & 21 & $0.87 \pm 0.05$ & $0.006 \pm 0.0007$ & 4.77 & -0.19 & $-8.03^{*}$ \\
& JF-2014 & 27 & 13 & 15 & $0.87 \pm 0.04$ & $0.005 \pm 0.0007$ & 4.02 & 0.11 & -3.15 \\
& TOTAL JFA & 63 & 31 & 25 & $0.88 \pm 0.04$ & $0.005 \pm 0.0005$ & 4.48 & -0.49 & $-18.55^{* *}$ \\
TOTAL & & 175 & 61 & 48 & $0.91 \pm 0.01$ & $0.007 \pm 0.0001$ & 5.70 & -0.99 & $-34.35^{*}$ \\
\hline
\end{tabular}

$\mathrm{N}$, number of sequences analyzed; $\mathrm{H}$, number of haplotypes; $\mathrm{S}$, number of segregating sites; $\mathrm{Hd}$, haplotype diversity ( \pm s.d.); $\pi$, nucleotide diversity ( \pm s.d); $K$, mean pairwise difference; Tajima's $D$ test and Fu's FS test . *Significant $p$-values $<0.05$; ${ }^{* *} p$-values $<0.001$. Codes for localities are given in Fig. 1

from those from the NCC (Table 3); therefore, JFA is considered as a different population from NCC. At temporal scale, there were no significant genetic differences for parasites from JFA between years, but parasites from NCC showed differences between site $\mathrm{CH}$ of year 2012 compared with AF and CQ of 2014 (Table 3).

\section{Demographic history}

The Z. seriolae haplotype network revealed the existence of two genetic groups: the first group showed one main ancestral haplotype (H5) occurring in each site and geographical area, but it was more predominant in JFA where $\mathrm{H} 5$ was surrounded by a large number of unique haplotypes. The group 2 included three highly frequent haplotypes $(\mathrm{H} 1, \mathrm{H} 2, \mathrm{H} 3)$ that were predominant in the NCC (Fig. 2).

The mismatch distribution for each site (graph not shown) and for entire geographical area of study deviated significantly from the expected distribution under expansion model, exhibiting a bimodal distribution of pairwise differences (Fig. 3). Neutrality test showed lack of significance of the Tajimas $D$ test $(D=-0.996, \mathrm{p}>0.1$; Table 1$)$, indicating that parasite populations are in equilibrium under the neutral model. Fu's test, however, was significantly negative (Table 1) for NCC and JFA parasite populations, suggesting the influence of some process affecting the demographical history of $Z$. seriolae.

\section{Population parameters, fecundity and body size}

Prevalence $\left(\mathrm{X}^{2}=31.7 ; \mathrm{df}=1 ; \mathrm{p}<0.001\right)$ and intensity $\left(U_{193,78}=5173.5 ; p<0.001\right)$ of $Z$. seriolae were significantly higher in JFA, considering the entire period of study (Table 4). In the NCC, the prevalence varied between $52.3 \%$ in year 2013 and $72.5 \%$ in year 2014. In JFA, the prevalence varied between 95 and $97 \%$ in years 2013 and 2014 respectively. Prevalence varied between

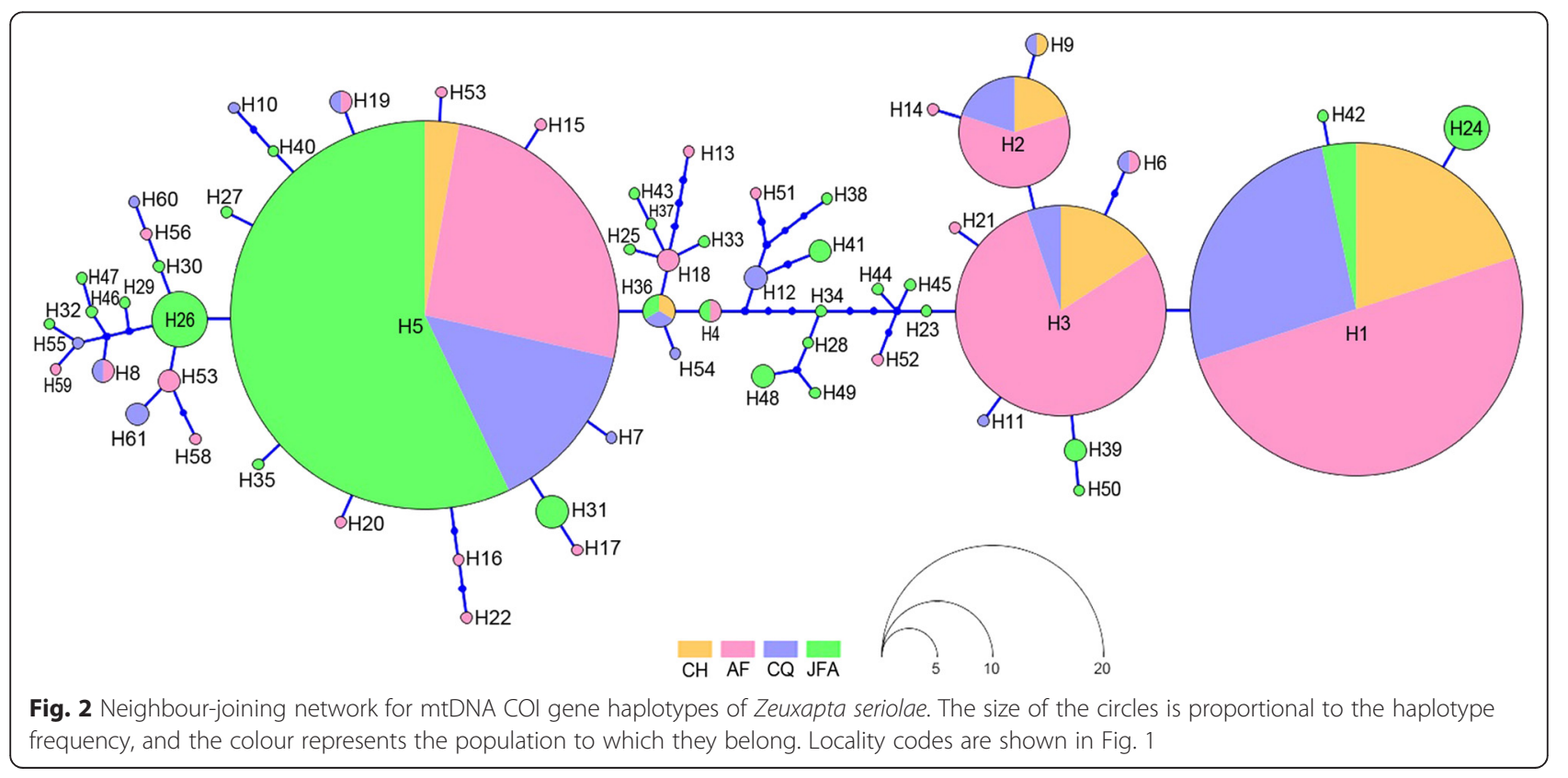


Table 2 Summary of hierarchical molecular variances analysis for Zeuxapta seriolae

\begin{tabular}{lllllll}
\hline Source of variation & d.f. & Sum of squares & Variance components & Percentage of variation & $F$ statistics & $P$ value \\
\hline Among years & 2 & 22.338 & -0.0229 & -0.79 & $F_{\text {ct }}=-0.0079$ & $0.4484 \pm 0.0052$ \\
Among populations within years & 3 & 45.048 & 0.3975 & 13.65 & $F_{\text {sc }}=0.1354$ & $0.0054 \pm 0.0008$ \\
Within populations & 169 & 428.928 & 2.5380 & 87.14 & $F_{\text {st }}=0.1286$ & $<<0.05$ \\
Total & 174 & 496.314 & 2.9726 & & \\
\hline
\end{tabular}

years within site AF in the coastal area $\left(\chi^{2}=4.96 ; \mathrm{df}=1\right.$; $p=0.02)$ but not in the oceanic area $\left(\chi^{2}=0.115 ; \mathrm{df}=1\right.$; $p=0.73)$. Among years, median intensity varied between 2 and 14 in the NCC and between 8 and 15 in the JFA (Table 4). A GLM showed that differences in intensity were affected for area $\left(x^{2}=41.6 ; p<0.001\right)$, year $\left(x^{2}=5.1\right.$; $p=0.02)$ and co-variable fish size $\left(\chi^{2}=101.9 ; \mathrm{p}<0.001\right)$.

Fecundity correlated with parasite body length $\left(\mathrm{r}_{\mathrm{s}}=\right.$ $0.156 ; n=341 ; p=0.003)$. Z . seriolae fecundity variations were explained by geographical area $\left(x^{2}=343.06 ; \mathrm{p}<\right.$ 0.001 ) and mostly by the co-variable parasite body length $\left(x^{2}=7743.03 ; \mathrm{p}<0.001\right)$.

Parasites from the JFA were significantly longer than those from the NCC (Table 4). The range of total $Z$. seriolae body length varied from 3.06 to $24.31 \mathrm{~mm}$ in the NCC and from 1.65 to $25.8 \mathrm{~mm}$ in the JFA. The first size at sexual maturity of $Z$. seriolae reached $11.8 \mathrm{~mm}$ in NCC, and at $14.4 \mathrm{~mm}$ in JFA (Fig. 4). Consequently, parasites from the JFA reached sexual maturity at higher body lengths.

\section{Discussion}

For the effective management and health maximization of cultured fish, it is essential to have a clear understanding of the levels of gene flow, the connectivity of parasite populations or metapopulations, the sources of larval infestations, and the relative fluxes of parasites between wild and farmed fish [1, 2]. To study these factors, genetic markers, such as mtDNA, have been widely used to detect population genetic structures [47, 48], which is useful for estimating the evolutionary potential of a parasite. Our results using the COI gene provide a geographical genetic structure for the monogenean Zeuxapta seriolae, with one population present in their host S. lalandi that approaches the coast in the summer and the other population in host fish from the oceanic area in the southeastern Pacific Ocean (SEP). This parasite population genetic structure may be explained by oceanographical barriers to parasite dispersion and/or by host population segregation.

Population structure in space and time is the result of both present processes and past history [49]. Populations that are established from small numbers of individuals tend to lose genetic variation due to increased effects of genetic drift [50]. However, successful colonization occurring during a long time period can accumulate new mutations, and species with relatively quick generation turnover, high fecundity and short lifespan like parasites can favour a fast rate of molecular evolution [51]. In our study, the bimodal mismatch distribution, which depends on the evolutionary history of one population [39], suggest that $Z$. seriolae populations are stable and consistent with populations that are geographically subdivided and have limited or low migration [52]. Additionally, network haplotype also suggests stable populations and are consistent with the lack of significance showed for neutrality Tajima's test. This test is based on the allele frequency distribution of segregating nucleotide sites [40], while Fu's test uses the distribution of alleles or haplotypes [41]; this last being considered the most sensitive test to detect some selection (or expansion) process [53]. Thus, the significant values in Fu's test indicate an excess of rare haplotypes what would be expected under neutrality (H5 connected to a high number of unique haplotypes), suggesting that in the past some purifying selection process on $Z$. seriolae populations $[41,54]$ has taken place, which could have occurred as a consequence of two possible scenarios:

Table 3 Pairwise $F_{S T}$ and p-values for test of population differentiation for Zeuxapta seriolae across Southeastern Pacific

\begin{tabular}{llllccrr}
\hline G.A. & Locality-year & CH-2012 & AF-2013 & AF-2014 & CQ-2014 & JF-2013 & JF-2014 \\
\hline NCC & CH-2012 & & 0.03821 & 0.1193 & 0.1745 & 0.4139 & 0.4702 \\
& AF-2013 & $0.15 \pm 0.01$ & & 0.0048 & 0.0259 & 0.2043 & 0.2367 \\
& AF-2014 & $0.035 \pm 0.006$ & $0.27 \pm 0.014$ & & -0.0050 & 0.1261 & 0.1562 \\
& CQ-2014 & $0.017 \pm 0.004$ & $0.13 \pm 0.01$ & $0.37 \pm 0.016$ & & 0.0521 & 0.0881 \\
JFA & JF-2013 & $<<0.001$ & $<<0.001$ & $0.0068 \pm 0.003$ & $0.044 \pm 0.006$ & 0.0144 \\
& JF-2014 & $<<0.001$ & $<<0.001$ & $0.0039 \pm 0.002$ & $0.030 \pm 0.005$ & $0.19 \pm 0.01$ & \\
\hline
\end{tabular}

F above diagonal; p-value below diagonal. Geographical Area: G.A.; Northern Chilean Coast (NCC): CH, AF, CQ; Juan Fernández Archipelago (JFA): JF 


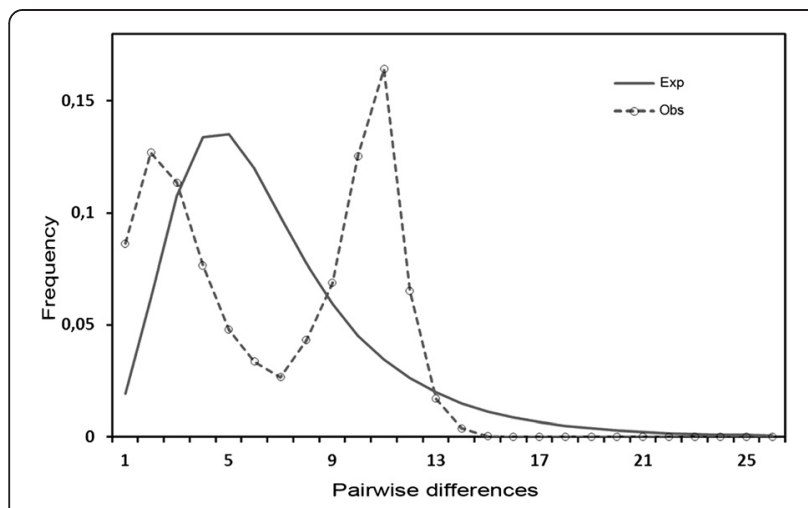

Fig. 3 Mismatch distributions of $\mathrm{COI}$ gene haplotypes for total samples of Zeuxapta seriolae. The graph was constructed using pairwise differences observed and expected under the expansion model

when host fish colonized oceanic Eastern island, therefore, introducing the parasites [55] or when parasites infecting migrant fish colonized fish from JFA. Likewise, the lower genetic diversity in parasite populations from JFA might be associated with 'founder effect' $[56,57]$ as has been suggested for the monogenean Mazocraeoides gonialosae along the coast of China [14].

Parasites infecting highly mobile hosts such as $S$. lalandi, could reach remote locations as well as its host. However, geographical barriers can affect either the host or parasite distribution $[20,58]$. JFA corresponds to islands of volcanic origin along hotspot lines of the Nazca Plate and emerged in the Plio-Pleistocene period, approximately 4 million years ago, [59]. These islands are located between the coastal and oceanic branches of the sub-Antarctic Peru or Humboldt Current, which is split by the subtropical Peruvian countercurrent [60]. Studies of the zoogeography of icthyofauna suggest that the JFA and other groups of oceanic islands in the SEP should be considered a biogeographic unit $[61,62]$. Until now, previous studies of other carangids, such as Trachurus murphyi [63], have not demonstrated that

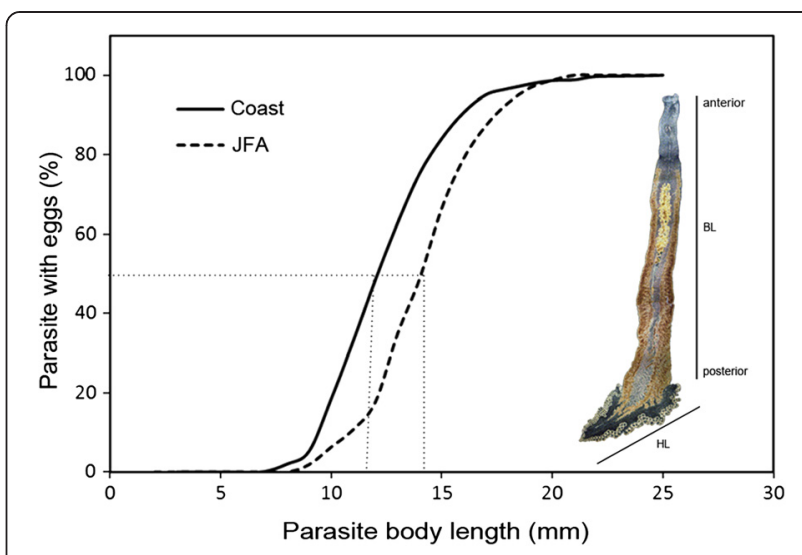

Fig. 4 First size of sexual maturity of Zeuxapta seriolae by geographical area. HL: haptor length and BL: body length

oceanographic barriers limit their dispersion and distribution in SEP. However, factors such as the Chile-Peru Current (Humboldt Current), surface gradients of temperature and salinity, and the great depths of the Chile-Peru Trench (more than $4000 \mathrm{~m}$ in the region) $[64,65]$ may impose barriers to the dispersion of parasites and may thus explain the genetic structure detected in the $Z$. seriolae population there.

The dispersal ability and genetic flow of ectoparasites is influenced by host specificity [66]. Host specificity is a key property of parasites because it is a determinant of their local extinction risk and their likelihood for successful establishment following introduction to a new region, with generalist species less prone to local extinction and better invaders than specialists [67]. The monogeneans $M$. gonialosae and Gotocotyla sawara, which are considered generalist parasites that infect more than one host fish species, did not show a geographical genetic structure based on COI mtDNA in the western Pacific Ocean. The absence of different genetic structures between the populations of these parasite species was attributed to a high gene flow favoured by their host

Table 4 Population parameters and biological traits for Zeuxapta seriolae across the Southern Pacific

\begin{tabular}{llllllll}
\hline Area & Site-year & $N_{H}$ & P\% & I (MI) & $N_{P}$ & PBL $( \pm$ sd $)$ & F (MF) \\
\hline NCC & CH-2012 & 54 & 70.37 & $1-100(6.5)$ & 72 & $12.82(2.2)$ & $50-1112(135)$ \\
& AF-2013 & 154 & 52.38 & $1-91(2)$ & 68 & $14.12(3.2)$ & $51-789(216)$ \\
& AF2014 & 66 & 68.18 & $1-131(4)$ & 14 & $19.9(3.9)$ & $64-862(305)$ \\
& CQ-2014 & 39 & 72.5 & $1-108(14)$ & 23 & $17.77(3.5)$ & $60-1347(282)$ \\
& TOTAL NCC & 313 & 61.98 & $1-131(3)$ & 177 & $14.56(3.7)$ & $50-1347(189)$ \\
JFA & JF-2013 & 20 & 95 & $5-55(15)$ & 105 & $15.3(2.4)$ & $54-1085(265)$ \\
& JF-2014 & 60 & 96.67 & $1-25(8)$ & 23 & $13.49(2.0)$ & $53-612(259)$ \\
& TOTAL JFA & 80 & 96.25 & $1-55(10)$ & 128 & $14.98(2.4)$ & $53-1085(259)$ \\
\hline
\end{tabular}

Prevalence (P\%), intensity range (I), mean parasite body length (PBL), fecundity range (F) per site, year and total period of study. MI, median intensity; MF, median fecundity; $\mathrm{N}_{\mathrm{H}}$, number of examined hosts; $\mathrm{N}_{\mathrm{P}}$, number of examined parasites; s.d, standard deviation 
range $[14,15]$. The dispersion stages of $Z$. seriolae consist of a string of eggs that can entangle in the gills of fish or join together to form light masses of numerous eggs that have a wide surface area, which allows the eggs to stay in the water column for a short time [28], with passive dispersion and free-swimming larvae that live approximately $24 \mathrm{~h}$ (personal obs.). The short lifetime of these developmental stages in the water column, their passive mode of dispersion and their high host specificity may decrease the probability of encountering a suitable host that favours their dispersal and genetic flow across an extensive geographical area. These parasite characteristics suggest a low degree of parasite migration between host populations, which may contribute to local adaptations [68].

Host behaviour is an important factor for parasite dispersal [9]. Therefore, hosts with an interrupted geographical distribution will affect the gene flow of their parasites [69]. S. lalandi is a cosmopolitan species distributed in the Pacific, Indian and Atlantic Oceans (www.fishbase.org). This species arrives at the NCC annually between December and April, where it is captured by artisanal fishermen, whereas $S$. lalandi is captured in the JFA year-round. In other geographical areas, $S$. lalandi shows a reproductive strategy with limited migration; specifically, only a subset of the reproductive fish migrates [70]. Additionally, tagging studies conducted in Australia suggest that S. lalandi can migrate considerable distances, but most juveniles are relatively sedentary $[23,71]$. However, spawning and nursery areas of $S$. lalandi are unknown in the SEP, the geographical genetic differences between $Z$. seriolae from JFA and NCC as well as the temporal genetic differentiation of $Z$. seriolae between localities from NCC could be indicative of different host subpopulations. Alternatively, the short generation time of the parasites combined with the subdivision of the host populations during prolonged time periods may contribute to the generation of structured parasite populations.

Throughout a latitudinal gradient, variations in environmental parameters, such as temperature and salinity, can modify the biological traits of a species [72, 73]. Monogenean biological traits vary according to environmental parameters, such as temperature and salinity, resulting in individuals achieving sexual maturity more quickly at warmer temperatures [20, 74-76]. Z. seriolae from the NCC area showed a smaller first size at sexual maturity and was significantly smaller and produced fewer eggs than did parasites from the JFA. Tubbs et al. [20] suggested an optimal temperature of $17.5^{\circ} \mathrm{C}$ for the in vitro fecundity of $Z$. seriolae because egg production decreases at other temperatures yet sexual maturity is reached more quickly at higher temperatures. The seawater in NCC varies between $18{ }^{\circ} \mathrm{C}$ and $20{ }^{\circ} \mathrm{C}$ in summer [77] and between
$14{ }^{\circ} \mathrm{C}$ (winter-autumn) and $20^{\circ} \mathrm{C}$ (spring-summer) in the waters of JFA [78]. Therefore, it is possible that the local environmental conditions can modify the biological traits of $Z$. seriolae populations across the SEP; however, it is also possible that genetic differences among the parasite populations are reflected in different biological traits. Regardless, the biological trait differences between populations of $Z$. seriolae may involve differential infestation dynamics (i.e. duration of parasite life cycles, infestation rates and parasite loads) on host populations from different geographical areas, as demonstrated for different ectoparasites in fish farming [20, 79, 80]. Similarly, the lower first size at sexual maturity in the NCC is predictive of shorter life cycles of this parasite in this area and probably quickly re-infests, which is associated with high densities of fish in captivity increasing the risk of outbreaks of this disease in farming $[81,82]$.

\section{Conclusions}

In this study, we detected two different populations of the parasite $Z$. seriolae infesting the wild fish S. lalandi across the SEP. In each area, the parasites showed different biological characteristics, such as fecundity, body size, and size at first sexual maturity, and population parameters suggesting different dynamics of infestation. Because of the seasonal migration of wild hosts in the SEP, and consequent temporal contact with farmed hosts in NCC, the quantification of diversity and genetic differentiation and level of gene flow (or isolation) between parasite populations, as well as potential parasite adaptations, is useful for fish health management in farming. The smallest sizes of sexual maturity observed in parasites from the NCC predict shorter life cycles, which along with the high genetic diversity suggest high evolutionary potential and high transmission of this parasite to farmed hosts.

\section{Abbreviations}

COI: Cytochrome c oxidase I; NCC: Northern Chilean coast; JFA: Juan Fernandez Archipelago; SEP: South-eastern Pacific Ocean; AF: Antofagasta; $\mathrm{CH}$ : Chañaral; $\mathrm{CQ}$ : Coquimbo.

\section{Competing interests}

The authors declare that they have no competing interests.

\section{Authors' contributions}

FAS: Designed the study, performed the molecular analysis and drafted the manuscript. MTG: designed the study, performed the statistical analysis and helped to draft the manuscript. Both authors read and approved the final manuscript.

\section{Acknowledgments}

Authors would like to thank the anonymous reviewers whose comments helped to improve this manuscript. This research was supported by project FONDECYT 1130629 granted to MTG. FAS thanks to scholarship CONICYT 21100414

\section{Author details}

${ }^{1}$ Programa Ciencias Aplicadas, mención Sistemas Marinos Costeros, Universidad de Antofagasta, P.O. Box 170, Antofagasta 1240000, Chile ${ }^{2}$ Instituto de Ciencias Naturales "Alexander von Humboldt", Facultad de 
Ciencias del Mar y Recursos Biológicos, Universidad de Antofagasta, Antofagasta 1240000, Chile.

\section{Received: 7 March 2015 Accepted: 8 May 2015} Published online: 22 May 2015

\section{References}

1. Todd C, Walker A, Ritchie M, Graves J, Walker A. Population genetic differentiation of sea lice (Lepeophtheirus salmonis) parasitic on Atlantic and Pacific salmonids: analyses of microsatellite DNA variation among wild and farmed hosts. Can J Fish Aquat Sci. 2004;61:1176-90.

2. Messmer A, Rondeau E, Jantzen S, Lubieniecki K, Davidson W, Koop B. Assessment of population structure in Pacific Lepeophtheirus salmonis (Krøyer) using single nucleotide polymorphism and microsatellite genetic markers. Aquaculture. 2011;320:183-92.

3. Allendorf $F$, Phelf $S$. Use of allelic frequencies to describe population structure. Can J Fish Aquat Sci. 1981;38:1507-14.

4. Palumbi S. Genetic divergence, reproductive isolation, and marine speciation. Annu Rev Ecol Syst. 1994;25:547-72.

5. Planes S, Fauvelot C. Isolation by distance and vicariance drive genetic structure of a coral reef fish in the Pacific Ocean. Evolution. 2002:56(2):378-99.

6. Freeland J, Kirk H, Petersen S. Molecular Ecology. 2nd ed. Chichester, UK: Wiley-Blackwell; 2011.

7. Slatkin M. Gene flow in natural populations. Ann Rev Ecol Syst. 1985:16:393-430

8. Slatkin M. Gene flow and the geographic structure of natural populations. Science. 1987;236:787-92

9. Huyse T, Poulin R, Theron A. Speciation in parasites: a population genetics approach. Trends Parasitol. 2005;21:469-75.

10. Blasco-Costa I, Waters J, Poulin R. Swimming against the current: genetic structure, host mobility and the drift paradox in trematode parasites. Mol Ecol. 2012;21:207-17.

11. Blouin M, Yowell C, Courtney C, Dame J. Host movement and the genetic structure of populations of parasitic nematodes. Genetics. 1995;141:1007-14.

12. Barret $L$, Thrall $P$, Burdon J, Linde $C$. Life history determines genetic structure and evolutionary potential of host-parasite interactions. Trends Ecol Evol. 2008;23(12):678-85.

13. MacDonald B, Linde C. Pathogen population genetics, evolutionary potential and durable resistance. Annu Rev Phytopathol. 2002;40:349-79.

14. Li M, Shi S, Brown C, Yang T. Phylogeographical pattern of Mazocraeoides gonialosae (Monogenea, Mazocraeidae) on the dotted gizzard shad, Konosirus punctatus, along the coast of China. Int J Parasitol. 2011:41:1263-72

15. Shi S, Li M, Yan S, Wang M, Yang C, Lun Z, et al. Phylogeography and demographic history of Gotocotyla sawara (Monogenea: Gotocotylidae) on japanese spanish mackerel (Scomberomorus niphonius) along the coast of china. J Parasitol. 2014;100:85-92.

16. Criscione C, Blouin M. Life cycles shape parasite evolution: comparative population genetics of salmon trematodes. Evolution. 2004;58(1):198-202.

17. Wu S, Wang G, Xi B, Xiong F, Liu T, Nie P. Population genetic structure of the parasitic nematode Camallanus cotti inferred from DNA sequences of ITS1 rDNA and the mitochondrial COI gene. Vet Parasitol. 2009;164:248-56.

18. Criscione C, Blouin M. Parasite phylogeographical congruence with salmon host evolutionarily significant units: implications for salmon conservation. Mol Ecol. 2007;16:993-1005.

19. López Z, Cardenas L, Runil F, González MT. Contrasting definitive hosts as determinants of the genetic structure in a parasite with complex life cycle along the south-eastern Pacific. Mol Ecol. 2015;24:1060-73.

20. Tubbs L, Poortenaar C, Sewell M, Diggles B. Effects of temperature on fecundity in vitro, egg hatching and reproductive development of Benedenia seriolae and Zeuxapta seriolae (Monogenea) parasitic on yellowtail kingfish Seriola lalandi. Int J Parasitol. 2005;35:315-27.

21. Mooney A, Ernst I, Whittington I. An egg-laying rhythm in Zeuxapta seriolae (Monogenea: Heteraxinidae), a gill parasite of yellowtail kingfish (Seriola lalandi). Aquaculture. 2006;253:10-6

22. Bravo S, Erranz F, Lagos C. A comparison of sea lice, Caligus rogercresseyi, fecundity in four areas in southern Chile. J Fish Diseases. 2009:32:107-13.

23. Hutson K, Ernst I, Mooney A, Whittington I. Metazoan parasite assemblages of wild Seriola lalandi (Carangidae) from eastern and southern Australia. Parasitol Int. 2007;56:95-105.
24. Sharp N, Poortenaar C, Diggles B, Willis T. Metazoan parasites of yellowtail kingfish, Seriola lalandi lalandi, in New Zealand: prevalance, intensity, and site preference. New Zeal J Mar Fresh. 2003;37:273-82.

25. Grau A, Crespo S, Pastor E, González P, Carbonell E. High infection by Zeuxapta seriolae (Monogenea: Heteraxinidae) associated with mass mortalities of amberjack Seriola dumerili Risso reared in sea cages in the Balearic Islands (western Mediterranean). Bull Eur Assoc Fish Pathol. 2003;23:139-42.

26. Stuart K, Drawbridge M. Captive spawning and larval rearing of California yellowtail (Seriola lalandi). Aquacult Res. 2013;44:728-37.

27. Montero F, Crespo S, Padro F, Gándara F, García A, Raga J. Effects of the gill parasite Zeuxapta seriolae (Monogenea: Heteraxinidae) on the amberjack Seriola dumerili Risso (Teleostei: Carangidae). Aquaculture. 2004;232:153-63.

28. Lia R, Zizzo N, Tinelli A, Lionetti A, Cantacessi C, Otranto D. Mass mortality in wild greater amberjack (Seriola dumerili) infected by Zeuxapta seriolae (Monogenea: Heteraxinidae) in the Jonian Sea. Bull Eur Assoc Fish Pathol. 2007:27(3):108-11.

29. Mansell B, Powell M, Ernst I, Nowak B. Effects of the gill monogenean Zeuxapta seriolae (Meserve, 1938) and treatment with hydrogen peroxide on pathophysiology of kingfish, Seriola lalandi Valenciennes, 1833. J Fish Diseases. 2005;28:253-62.

30. Ogawa K, Yokohama H. Parasitic diseases of cultured marine fish in Japan. Fish Pathol. 1998:33:303-9.

31. Vergani M, Acha E, Diaz De Astarlon J, Giberto D. Food of the yellowtail amberjack Seriola lalandi from the south-west Atlantic. J Mar Biol Assoc UK. 2008;88(4):581-852.

32. Leung T, Donald K, Keeney D, Koehler A, Peoples R, Poulin R. Trematode parasites of Otago Harbour (New Zealand) soft-sediment intertidal ecosystems: life cycles, ecological roles and DNA barcodes. New Zeal J Mar Fresh. 2009:43:857-65.

33. Filatov D. Proseq: A software for preparation and evolutionary analysis of DNA sequence data sets. Mol Ecol Notes. 2002;2:621-4.

34. Larkin M, Blackshields G, Brown N, Chenna R, McGettigan P, McWilliam H, et al. Clustal W and Clustal X version 2.0. Bioinformatics. 2007;23:2947-8.

35. Nei M. Molecular evolutionary genetics. New York, New York: Columbia University Press; 1987. p. 255-86.

36. Librado P, Rozas J. DnaSP v5: A software for comprehensive analysis of DNA polymorphism data. Bioinformatics. 2009;25:1451-2

37. Excoffier L, Laval G, Schneider S. Arlequin (version 3.0): an integrated software package for population genetics data analysis. Evol Bioinform Online. 2005;1:47-50

38. Tamura K, Stecher G, Peterson D, Filipski A, Kumar S. MEGA6: Molecular evolutionary genetics analysis version 6.0. Mol Biol Evol. 2013;30:2725-9.

39. Rogers $\mathrm{A}$, Harpending $\mathrm{H}$. Population growth makes waves in the distribution of pairwise genetic differences. Mol Biol Evol. 1992;9(3):552-69.

40. Tajima F. Statistical method for testing the neutral mutation hypothesis by DNA polymorphism. Genetics. 1989;123:585-95.

41. Fu Y. Statistical tests of neutrality of mutations against population growth, hitchhiking and background selection. Genetics. 1997;147:915-25.

42. Depaulis F, Mousset S, Veuille M. Power of neutrality tests to detect bottlenecks and hitchhiking. J Mol Evol. 2003;57:190-200.

43. Bush A, Lafferty K, Lotz J, Shostak A. Parasitology meets ecology on its own terms: Margolis et al. revisited. J Parasitol. 1997;83:575-83.

44. Zar J. Biostatistical analysis. Thirdth ed. New Jersey, USA: Prentice-Hall; 1996

45. Somerton D. A computer technique for estimating the size of sexual maturity in crabs. Can J Fish Aquat Sci. 1980;37:1488-94.

46. Venables W, Ripley B. Modern applied statistics with Statistics and computing. Fourthth ed. New York, USA: Springer; 2002.

47. Mladineo I, Šegvić T, Grubišić L. Molecular evidence for the lack of transmission of the monogenean Sparicotyle chrysophrii (Monogenea, Polyopisthocotylea) and isopod Ceratothoa oestroides (Crustacea, Cymothoidae) between wild bogue (Boops boops) and cage-reared sea bream (Sparus aurata) and sea bass (Dicentrarchus labrax). Aquaculture. 2009;295(3-4):160-7.

48. Falk B, Perkins S. Host specificity shapes population structure of pinworm parasites in Caribbean reptiles. Mol Ecol. 2013;22:4576-90

49. Hewitt G, Butlin R. Causes and consequences of population structure. In: Krebs J, Davies N, editors. Behavioural Ecology: An Evolutionary Approach. Oxford: Blackwell; 1997. p. 350-72.

50. Lande R. Genetics and demography in biological conservation. Science. 1988;241:1455-60. 
51. Kanŭch P, Berggren $\AA$, Cassel-Lundhagen A. Genetic diversity of a successful colonizer: isolated populations of Metrioptera roeselii regain variation at an unusually rapid rate. Ecol Evol. 2014;4(7):1117-26.

52. Marjoriam P, Donnelly P. Pairwise comparisons of mitochondrial DNA sequences in subdivided populations and implications for early human evolution. Genetics. 1994;136:673-83.

53. Ramos S, Rozas J. Statistical properties of new neutrality tests against population growth. Mol Biol Evol. 2002;19(12):2092-100

54. Donnelly M, Licht M, Lehmann T. Evidence for recent population expansion in the evolutionary history of the malaria vectors Anopheles arabiensis and Anopheles gambiae. Mol Biol Evol. 2001;18(7):1353-64.

55. Von Ihering $\mathrm{H}$. On the ancient relations between New Zealand and South America. Trans New Zealand Inst. 1891;24:431-45.

56. Austerlitz F, Jung-Muller B, Godelle B, Gouyon P. Evolution of coalescence times, genetic diversity and structure during colonization. Theor Popul Biol. 1997:51:148-64.

57. Hewitt G. Post-glacial re-colonization of European biota. Biol J Linn Soc. 1999;68:87-112.

58. Miller P, Fitch A, Gardner M, Hutson K, Mair G. Genetic population structure of Yellowtail Kingfish (Seriola lalandi) in temperate Australasian waters inferred from microsatellite markers and mitochondrial DNA. Aquaculture. 2011;319(3-4):328-36.

59. Stuessy T, Foland K, Sutter J, Sanders R, Silva M. Botanical and geological significance of potassium-argon dates from Juan Fernández Islands. Science. 1984;225:49-51.

60. Arana P. Perspectivas históricas y proyecciones de la actividad pesquera realizada en el Archipiélago de Juan Fernández, Chile. In: Castilla JC, editor. Islas oceánicas chilenas: conocimiento científico y necesidades de investigaciones. Chile: Ediciones Universidad Católica de Chile; 1987. p. 319-53.

61. Pequeño G, Lamilla J. The littoral fish assemblage of the Desventuradas Islands (Chile), has zoogeographical affinities with the Western Pacific. Global Ecol Biogeogr. 2000;9:431-7.

62. Dyer B, Westneat M. Taxonomy and biogeography of the coastal fishes of Juan Fernández Archipielago and Desventuradas Islands. Chile Rev Biol Mar Oceanogr. 2010;45(S1):589-617.

63. Cárdenas L, Silva A, Magoulas A, Cabezas J, Poulin E, Ojeda P. Genetic population structure in the Chilean jack mackerel, Trachurus murphyi (Nichols) across the South-eastern Pacific Ocean. Fish Res. 2009;100:109-15.

64. Pequeño G, Lamilla J. Desventuradas Islands, Chile, the easternmost outpost of the Indo-West Pacific zoogeographic region. Rev Biol Trop. 1996;44:929-31.

65. Pequeño G, Lamilla J. Fishes of the family Serranidae in the Desventuradas Islands, Chile (Osteichthyes, Perciformes). Bol Soc Biol Concepc. 1996;67:22-32

66. Johnson K, Williams B, Drown D, Adams R, Clayton D. The population genetics of host specificity: genetic differentiation in dove lice (Insecta: Phthiraptera). Mol Ecol. 2002;11:25-38.

67. Bush A, Kennedy C. Host fragmentation and helminth parasites: Hedging your bets against extinction. Int J Parasitol. 1994;24:1333-43.

68. Lively C. Migration, virulence, and the geographic mosaic of adaptation by parasites. Amer Naturalist. 1999;153:34-47.

69. Glennon V, Perkins E, Chisholm L, Whittington I. Comparative phylogeography reveals host generalists, specialists and cryptic diversity: hexabothriid, microbothriid and monocotylid monogeneans from rhinobatid rays in southern Australia. Int J Parasitol. 2008;38:1599-612.

70. Garrat P. Notes on seasonal abundance and spawning of some important offshore linefish in Natal and Transkei waters, Southern Africa. S Afr J Mar Sci. 1988:7:1-8

71. Gillanders B, Ferrell D, Andrew N. Estimates of movement and life history parameters of yellowtail kingfish (Seriola lalandi): how useful are data from a cooperative tagging programme? Mar Freshwater Res. 2001;52:179-92.

72. Leggett W, Carscadden J. Latitudinal variation in reproductive characteristics of American shad (Alosa sapidissima): Evidence for population specific life history strategies in fish. J Fish Res Board Can. 1978;35(11):1469-78.

73. Heibo E, Magnhagen C, Asbjørn L. Latitudinal variation in life-history traits in Eurasian perch. Ecology. 2005;86:3377-86.

74. Kearn G, Ogawa K, Maeno Y. Egg production, the oncomiracidium and larval development of Benedenia seriolae, a skin parasite of the yellowtail, Seriola quinqueradiata, in Japan. Publ Seto Mar Biol Lab. 1992;35(6):351-62.
75. Ogawa K. Development of Bivagina tai Monogenea: Microcotylidae. Nippon Suisan Gakkaishi-Bull. Jpn Soc Sci Fish. 1988;54(1):61-4.

76. Yoshinaga T, Segawa I, Kamaishi T, Sorimachi M. Effects of temperature, salinity and chlorine treatment on egg hatching of the monogenean Neoheterobothrium hirame infecting Japanese flounder. Fish Pathol. 2000;35(2):85-8

77. Blanco J, Thomas A, Carr M, Strub P. Seasonal climatology of hydrographic conditions in the upwelling region off Northern Chile. J Geophys Res. 2001;106(6):451-67.

78. Palma A, Cáceres I, Bennett R, Magnolfi S, Henríquez L, Guerra J, et al. Near-shore distribution of phyllosomas of the two only lobster species (Decapoda: Achelata) present in Robinson Crusoe Island and endemic to the Juan Fernández archipelago. Rev Chil Hist Nat. 2011;84:379-90.

79. Gonzalez L, Carvajal J. Life cycle of Caligus rogercresseyi, (Copepoda: Caligidae) parasite of Chilean reared salmonids. Aquaculture. 2003;220(1-4):101-17.

80. Costello M. Ecology of sea lice parasitic on farmed and wild fish. Trends Parasitol. 2006;22:475-83.

81. Thoney D, Hargis W. Monogenea (Platyhelminthes) as hazards for fish in confinement. Annu Rev Fish Dis. 1991;1:133-53.

82. Nowak B. Parasitic diseases in marine cage culture - An example of experimental evolution of parasites? Int J Parasitol. 2007;37:581-8.

\section{Submit your next manuscript to BioMed Central and take full advantage of:}

- Convenient online submission

- Thorough peer review

- No space constraints or color figure charges

- Immediate publication on acceptance

- Inclusion in PubMed, CAS, Scopus and Google Scholar

- Research which is freely available for redistribution 